\title{
Further observations on the role of nitric oxide in the feline lateral geniculate nucleus
}

\author{
J. Cudeiro, C. Rivadulla, R. Rodríguez, S. Martínez-Conde, L. Martínez, K.L. Grieve, \\ C. Acuña
}

\begin{abstract}
We have examined the responses of a population of 77 cells in the dorsal lateral geniculate nucleus (dLGN) of the anaesthetized, paralysed cat. Here the synthetic enzyme for the production of nitric oxide, nitric oxide synthase, is found only in the presynaptic terminals of the cholinergic input from the brainstem. In our hands, iontophoretic application of inhibitors of this enzyme resulted both in significant decreases in visual responses and decreased responses to exogenous application of NMDA, effects which were reversed by coapplication of the natural substrate for nitric oxide synthase, L-arginine, but not the biologically inactive isomer, D-arginine. Nitroprusside and $S$ nitroso- $N$-acetylpenicillamine (SNAP), nitric oxide donors, but not L-arginine, were able to increase markedly both spontaneous activity and the responsiveness to NMDA application. Furthermore, SNAP application facilitated visual responses. Responses of cells in animals without retinal, cortical and parabrachial input to the LGN suggest a postsynaptic site of action of nitric oxide. This modulation of the gain of visual signals transmitted to the cortex suggests a completely novel pathway for nitric oxide regulation of function, as yet described only in primary sensory thalamus of the mammalian central nervous system.
\end{abstract}

Keywords: cat, visual system, neuromodulation, parabrachial input

\section{Introduction}

The dorsal lateral geniculate nucleus (dLGN) of the cat is a major target of output from the retina, and in recent years there has been a large amount of work directed towards isolating the functional significance of the complex synaptic physiology of this nucleus (Murphy and Sillito, 1987; Funke and Eyse11992; Sillito et al., 1993; Lo and Sherman 1994; Sillito et al., 1994). Besides the visually specific pathways involving this nucleus, there exist a number of modulatory pathways considered to influence the activity of dLGN cells more globally, having putative roles in sleep/wake and arousal states (for reviews see Singer, 1977; Steriade and Llinas, 1988; McCormick, 1992). One such pathway is the cholinergic pathway from the parabrachial nucleus of the brainstem, activity of which releases acetylcholine (ACh) within the dLGN; ACh is known to excite dLGN relay cells directly (Sillito et al., 1983; Eysel et al., 1986; McConhick and Pape, 1988). Interesting1y, recent evidence has shown that within the feline dLGN there is a unique distribution of nitric oxide synthase (NOS), the enzyme responsible for the production of nitric oxide. NOS is found exclusively within the ACh-containing fibres arising in the parabrachium (Bickford et al., 1993). Since nitric oxide is now considered to be a widely spread CNS neuromodulatory substance, which is also a highly diffusible -gaseous compound (for reviews see Garthwaite, 1991; Moncada et al., 1991; Snyder and Bredt, 1991; Schuman and Madison, 1994), this represents a novel colocalization of neurotransmitter substances. Nitric oxide is produced from L-arginine by the action of NOS, and has traditionally been viewed as a retrograde messenger, diffusing from postsynaptic structures to act remotely, for example on presynaptic terminals (Garthwaite et al., 1988; Garthwaite, 1991; O'De11 et al., 1991; Snyder and Bredt, 1991). It has been suggested that nitric oxide is involved in glutamate mediated neurotoxicity, by increasing synaptic release of the excitant (Dawson et al., 1991, 1993), Other evidence, however, has favoured the view that nitric oxide may act to reduce NMDA-mediated neurotoxicity, by an action directly on NMDA receptor configuration (Lei et al., 1992; Manzoni et al., 1992; Lipton et al., 1993).

We have recently presented preliminary evidence using iontophoretic application of putative inhibitors of NOS, suggesting that, within the cat dLGN, nitric oxide acts to enhance visual responses, specifically and selectively enhancing NMDA-mediated excitation (Cudeiro et al., 1994a,b). Unlike the 
interaction of cotransmitters such as $\mathrm{ACh}$ and vasoactive intestinal peptide in the autonomic nervous system, where the colocalized peptide extends the effective range of activity of the classical neurotransmitter (Lundberg et al., 1980), in the dLGN nitric oxide seems to facilitate NMDA-mediated excitation selectively, without an apparent action on ACh-mediated activity (Cudeiro et al., 1994b). Activation of NMDA receptors is known to provide a major component of the retinal input to dLGN (Kemp and Sillito, 1982; Hartveit and Heggelund, 1990; Heggelund and Hartveit, 1990; Scharfman et al., 1990; Sil1ito et al., 1990a,b; Kwon et al., 1991). By these means nitric oxide may potent1y modulate visually driven activity. In this paper we examine further this effect of blockade of NOS in the cat dLGN, and examine the effect of application of nitric oxide donors.

\section{Materials and methods}

\section{Animal preparation}

Experiments were carried out on adult cats in the weight range $1.8-3.0 \mathrm{~kg}$. Animals were anaesthetized with ha1 othane in nitrous oxide (70\%) and oxygen (30\%); the concentration of ha1othane was $5 \%$ for induction. $1.5-2 \%$ for surgery and $0.1-0.5 \%$ for maintenance. To prevent eye movements, anima1s were paralysed with gallamine triethiodide (loading dose of $40 \mathrm{mg}$, maintenance $10 \mathrm{mg} / \mathrm{kg} / \mathrm{h} \mathrm{i.v}$. infusion). End-tidal $\mathrm{CO}_{2}$ levels, ECG waveform. intersystolic interval and the frequency of spindles in the EEG were monitored continuously throughout the experiment.

The rate and depth of artificial respiration were adjusted to maintain end-tidal $\mathrm{CO}_{2}$ at 3.8-4.2\%; the level of halothane was chosen to achieve a state of light anaesthesia. Once a stable state was reached, any variation in the monitored parameters commensurate with a change in the depth of anaesthesia was compensated for by alterations in the level of halothane. Wound margins were treated with lignocaine hydrochloride with adrenalin administered subcutaneously. Ear bars were coated with lignocaine gel. The eyes were treated with atropine methonitrate and phenylephrine hydrochloride, protected with zero power contact lenses and brought to focus on a semi-opaque tangent screen $57 \mathrm{~cm}$ distant. Visual stimuli were viewed monocularly through $3 \mathrm{~mm}$ artificial DUDils.

\section{Recording and iontophoretic application of drugs}

Seven-barrelled micropipettes were used for iontophoresis and pressure ejection of drugs and singleunit extracellular recording in the A laminae of the cat dLGN. Drug barrels contained a selection of the following solutions: $\mathrm{NaCI}$ ( $3 \mathrm{M}$ for recording), L-arginine (L-Arg, $10 \mathrm{mM}, \mathrm{pH}$ 6.0), D-arginine (D-Arg, $10 \mathrm{mM}, \mathrm{pH}$ 6.0), $N^{G}$-nitro-Larginine (L-NOArg, 0.1, I, $10 \mathrm{mM}, \mathrm{pH}$ 6.0), $N^{G}$-methyl-L-arginine (LMeArg, $10 \mathrm{mM}, \mathrm{pH}$ 6.0), sodium nitroprusside (applied by pressure ejection, $10 \mathrm{mM}$ ), S-nitroso-Nacetyl-DL-penicillamine (SNAP, applied by pressure ejection, $10 \mathrm{mM}$ ), NMDA (0.1 M, pH 8.0), yaminobutyric acid (GABA, $0.5 \mathrm{M}, \mathrm{pH} 3.5)$ or pontamine sky blue $(2 \% \mathrm{wt} / \mathrm{vol}$, in $0.5 \mathrm{M}$ sodium acetate solution, for histological reconstruction). Pipette tips were broken back to diameters ranging from 3 to 10 $\mu \mathrm{m}$, and each drug barrel was subject to a retention current of 5-25 nA of appropriate polarity.

\section{Visual stimulation and experimental design}

Cells were classified by a battery of tests into $\mathrm{X}$ and $\mathrm{y}$ groups of $\mathrm{ON}$ and OFF subtypes. Particular emphasis was placed on the linearity of spatial summation in the responses to sinusoidal gratings of the appropriate spatial frequency. Sinusoidally phase-reversed gratings were presented at a number of spatial phase positions in a randomized interleaved sequence, using the highest spatial frequency giving reliable responses. Fourier analysis produced first and second harmonic components of these responses which were plotted against spatial phase. X cell responses were characterized by a strongly phase- dependent first hannonic which exhibited a clear null point, while y cell responses included a second hannonic component which was not strongly phase-dependent. Other tests included the duration of the response to standing contrast over the receptive field centre, the presence or absence of a shift effect, the strength of surround antagonism and size of receptive field centre for a given eccentricity (Enroth-Cugell and Robson, 1967; Cleland et al., 1971; Derrington and Fuchs, 1979). Single-unit data were collected and visual stimuli were produced under computer control (Visua1 Stimulation System, Cambridge Electronic Design, Cambridge, UK). Stimuli routinely consisted of flashed spots of several diameters, moving bars of light of several lengths or sinusoidal gratings of different spatial frequencies drifted through the receptive field. Stimulus contrast $\left[\left(L_{\max }-L_{\min } /\left(L_{\max }+L_{\min }\right]\right.\right.$ was held within a non-saturating range, usually $0.36-0.7$, with a mean luminance of $14 \mathrm{~cd} / \mathrm{m}^{2}$. For quantitative assessment of receptive field 
parameters the multihistogram technique was used, and all stimuli (e.g. a moving bar of six different lengths) were randomly interleaved within each tria1. Our basic experimental paradigm involved establishing control responses to a range of visual stimuli. This was then repeated during continuous iontophoretic application of an inhibitor of nitric oxide synthesis (alone or in combination with D- or LArg). To examine the nature of the suppressive activity of NOS inhibitors on excitatory responses evoked by exogenously applied NMDA (Cudeiro et al., 1994b), we used pulsatile iontophoretic application of NMDA with different ejection currents before and during continuous application of either L-NOArg or LMeArg (again alone or in combination with D- or L-Arg). Typically, responses were averaged over five to seven trials and were assessed from the accumulated count in the binned peristimulus time histograms (PSTHs). Pressure application of the nitric oxide donors sodium nitroprusside or SNAP, a1one or in combination with NMDA, was also quantitatively exarnined in the same manner. Magnitude of the drug iontophoretic application current was selected on the basis of initial qualitative observations.

\section{Deafferented animals}

In order to minimize excitatory afferent synaptic input to the dLGN and remove presynaptic activity, four anima1s were decerebrated at the intercollicular level, the visual cortex (areas 17 and 18) was removed by aspiration, and the eye ipsilatera1 to the recording electrode surgica11y removed. Bipolar stimulating electrodes were first placed over the optic nerve ipsilateral to the hemisphere to be lesioned, and single monophasic pulses $(0.1 \mathrm{~ms}$ duration, up to $1 \mathrm{~mA})$ used to activate the dLGN orthodromica11y. Control responses to electrical activation were obtained prior to enucleation. Single-unit recording from these animals was begun only after a waiting period of up to $48 \mathrm{~h}$ after surgery, when release of neurotransmitter from retinal terminals was completely absent, as judged by the lack of response to stimulation of the optic nerve, even when stimulus current was increased to three times that which had been effective prior to enucleation. Clear visua11y elicited activity in the dLGN layer dominated by the intact eye was present at this time (inset in Fig. 6).

To control for possible anaesthetic influences, pentobarbitone was used in one animal $(1-4 \mathrm{mg} / \mathrm{kg} / \mathrm{h}$ i.v.), respired on room air; the effect of application of NOS inhibitors was unaffected. At the termination of each experiment, the animal was killed by an overdose of anaesthetic and the brain was removed and prepared for histologica1 reconstruction.

\section{Results}

\section{Effect of application of NOS inhibitors on visual responses}

For this study the effects of iontophoretic application of inhibitors of NOS have been tested on a population of 77 cells $(X=35, Y=38$, unclassified $=4)$ recorded in the A laminae of the dLGN. All cells had receptive fields within $12^{\circ}$ of the area centralis. A typical example of the effect of such application is shown in Figure 1. Here, the responses of an ON centre X cell to a flashed spot of light of optimum diameter centred on and restricted to the centre of the receptive field are shown. In the upper row, the control response to visual stimulation alone are compared to those elicited during continuous iontophoretic ejection of L-NOArg, showing the temporal progression of the effect of NOS blockade. The visual response clearly declined by some $47 \%$ after 3 min of application, and remained at this level during the subsequent test period. The initial transient response and the sustained component were equally affected, and spontaneous activity was reduced. In the middle row, this cell was again tested with the same visual stimulus, after a recovery period of $12 \mathrm{~min}$, and the effect of concornitantly ejecting both LNOArg and L-Arg during visual stimulation is illustrated. In this case, despite an equivalent application of the NOS inhibitor, neither visual response nor spontaneous activity were altered. Finally, after a repeated recovery period, L-NOArg was applied together with the biologically inactive isomer, D-Arg. Here, despite an equivalent application of a compound equal to L-Arg in all but stereochernistry, LNOarg again produced a marked inhibition of the visual response, reducing it by $50 \%$, producing an effect equivalent to application of L-NOArg alone. Another example is shown in Figure 2. In this case we show the responses of an $\mathrm{ON}$ y cell to flashed spots of light of different diameters, before during and after application of L-NOArg. As is typical of LGN cells, the control visual responses showed clear response summation followed by attenuation as diameter of the stimulus centred on the centre of the receptive field was increased. During application of the NOS inhibitor, L-NOArg, there were marked decrements in the visual responses (Fig. 2A, p $<0.000$, Wilcoxon test at optimum response), which were reversible and not stimulus-selective, completely in accord with our previous findings (Cudeiro et al., 1994a). Applied with L-NOArg, L-Arg (Fig. 2B, dotted line) entirely suppressed the effect of the NOS inhibitor, allowing 


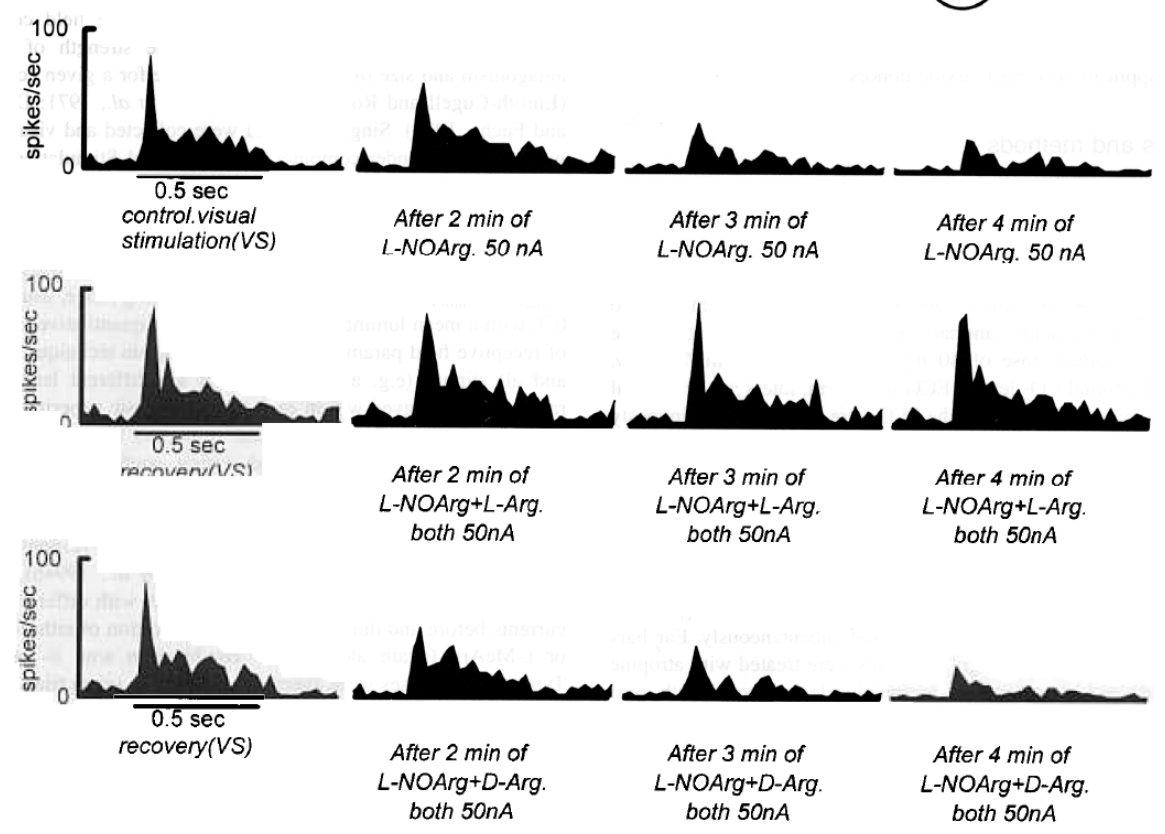

FIG. 1. Peristimulus time histograms (PSTHs) documenting the responses of an ON centre X cell to a spot of light flashed over the receptive field centre. The region of the field stimulated is indicated diagrammatically above the records. Spot diameter $1.25^{\circ}$. Upper records show the control responses of the cell and responses in the presence of L-NOArg continuously ejected (50 nA from a $10 \mathrm{mM}$ solution). In each case the response is the average of ten trials. Middle records show the responses of the same cell after a recovery period of $12 \mathrm{~min}$, to the same visual stimulus alone or during simultaneous ejection of L-NOArg and L-Arg (50 nA). The same paradigm is illustrated in the lowest records, but in this case D-Arg $(50 \mathrm{nA})$ was ejected with L-NOArg. Horizontal bars under the PSTHs indicate flash duration, $0.5 \mathrm{~s}$. Bin size $25 \mathrm{~ms}$.

complete expression of the normal visual responses, with unchanged visual specificity. Again this action was not seen when D-Arg was co-applied in place of L-Arg (Fig. 2B, broken line). We have seen such selective suppressive effects of application of NOS inhibitors regardless of the type of the visual stimulation used (and therefore of the synaptic mechanisms involved), and the effect was similar on all subpopulations of LGN cell types. On average, visual responses of the 46 cells tested were reduced by 49 $\pm 4 \%$ (SEM), $(\mathrm{P}<0.000$, Mann-Whitney $U$ test), and these data are given in Table I. We found no significant differences between groups. Routinely, responses to drug application were seen within 2-5 min after ejection was commenced and lasted 7-15 rnin after cessation. In all cases tested L-Arg reversed the effect of L-NOArg or L-MeArg, while D-Arg was consistently ineffective. 


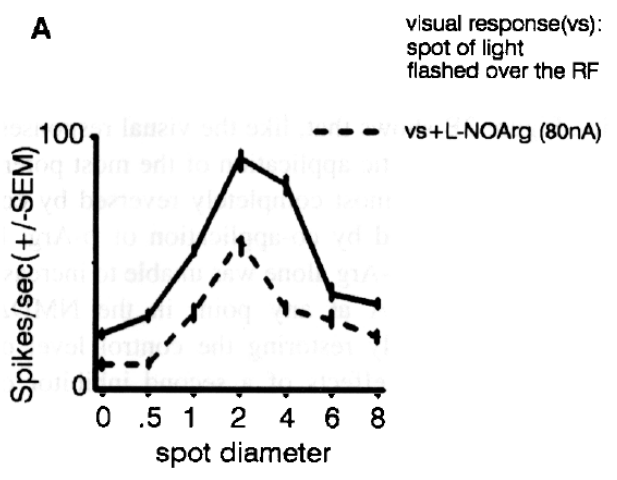

B

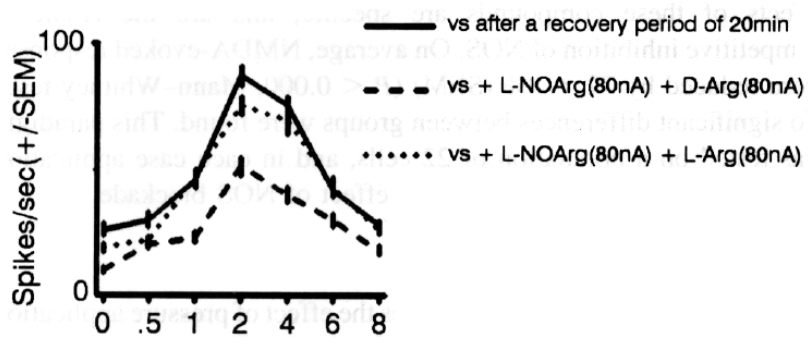

FIG. 2. Diameter-response curves for an ON y cell in the cat dLGN, stimulated with flashed spots of light of different diameters (in degrees of visual space) centred on its receptive field (RF). Visual stimuli were randomly interleaved within each trial. Response to stimulation with static spots of light is essentially unchanged in the absence of corticofugal input (Murphy and Sillito, 1987), suggesting that these responses are purely retinally driven, via NMDA and non-NMDA ionotropic, not metabotropic, receptors (McCormick and Von Krosigk, 1992). (A) Control tuning curve (solid line), and, overlying, tuning curve obtained during continuous iontophoretic application of L-NOArg (broken line). (B) Repeated control curve and responses during continuous application of L-NOArg concomitantly with D-Arg (broken line) and L-Arg (dotted line). The inhibitory effect of L-NOArg was completely blocked during L-Arg application but was unaffected by the inactive isomer D-Arg. Responses are averaged over seven trials. Small vertical bars, mean \pm SEM.

\section{Effect of application of NOS inhibitors on NMDA-evoked responses}

We have previously shown that application of an inhibitor of NOS decreased the responses of cells to exogenous application of NMDA (Cudeiro et al., 1994b). We have now examined in more detail this suppressive activity of NOS inhibitors, and this is illustrated in Figure 3. The control responses (Fig. 3A) illustrate a dose-response curve for application of NMDA using different application currents, from zero (spontaneous activity) to a maximum response at around 110-130 nA of applied NMDA. Co-application of L-NOArg from solutions of $0.1,1$ or $10 \mathrm{mM}$ effectively suppressed the NMDA mediated excitation in a dose-dependent manner, the dose-response curves showing no lateral shift on the $\mathrm{X}$ axis, and resulted in nearly complete suppression of NMDA-induced excitation when using the highest concentration. These applications also induced a decrease in spontaneous activity. Figure 3B shows that, like the visual responses, the suppressive effect of iontophoretic application of the most potent L-NOArg solution (10 $\mathrm{mM}$ ) was almost completely reversed by coapplication of L-Arg, but unaffected by co-application of DArg. It should be noted that application of L-Arg alone was unable to increase the excitatory responses to NMDA at any point in the NMDA dose-response curve, instead merely restoring the control level of responsiveness. In Figure 3C, the effects of a second inhibitor of NOS are illustrated. In this case, LMeArg (lo mM) also markedly suppressed the NMDA induced excitations. The lack of effect of D-Arg, and effect of L-Arg in restoring but not enhancing the activity of NMDA are again shown, reinforcing the view that the suppressive effects of these compounds are specific, and are the result of competitive inhibition of NOS. On average, NMDA-evoked responses were reduced by $72 \pm 8 \%$ (SEM) (P < 0.000 , Mann-Whitney test). No significant differences between groups were found. This paradigm was tested on a population of 22 cells, and in each case application of D-Arg was unable to reverse the effect of NOS blockade. 
A

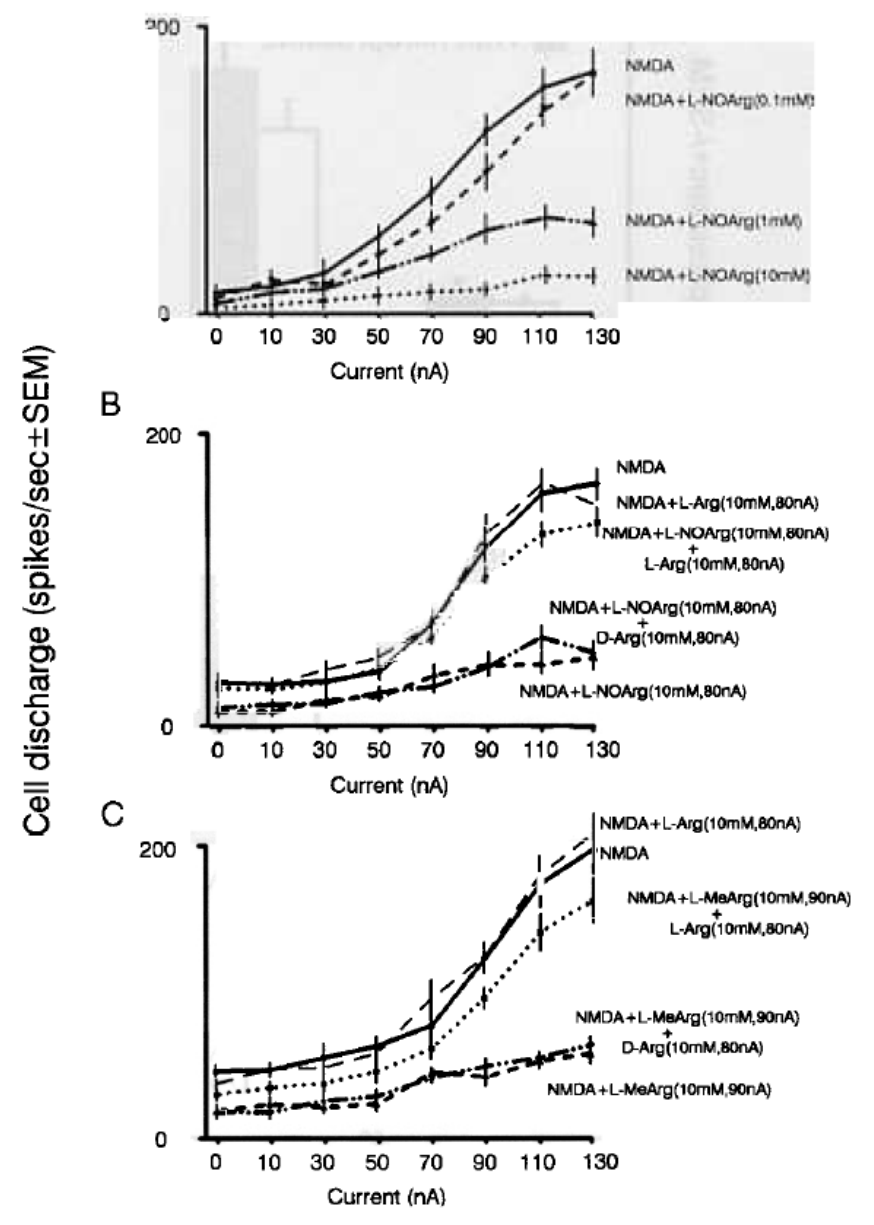

FIG. 3. Dose-response curve for NMDA iontophoretically applied to two dLGN cells. (A) Control responses to application of NMDA, using different ejection currents (nA), (splid line. drug pulse duration $5 \mathrm{~s}$ ) and repeated in the presence of a continuous 80 $\mathrm{nA}$ ejection OfL-NOArg at three concentrations $(0.1 \mathrm{mM}$, broken line, $1 \mathrm{mM}$. chained line. $10 \mathrm{mM}$, dotted line). L-NOArg blocked the response to NMDA in a dose-dependent fashion. (B) Responses of the same cell when subsequently retested with NMDA (solid line). and again to NMDA combined with L-NOArg (broken line). Now. however, when NMDA was ejected together with both LNOArg and L-Arg (dotted line), the inhibitory effect of L-NOArg was blocked. The physiologically inactive isomer D-Arg was without effect (chained line). L-Arg alone produced no change in the NMDA-evoked responses (discontinuous fine line). Between curves there were recovery periods of $-10-15 \mathrm{~min}$. (C) Application of a second inhibitor of NOS. L-MeArg. to a second ce11 produced similar effects.

\section{Application of NO donors}

The histogram in Figure 4A illustrates the effect of pressure application of the nitric oxide donor sodium nitroprusside. Perhaps surprising in view of the action of L-Arg, in this population of nine cells (Fig. 4A, filled column, right side) co-application of nitroprusside with NMDA significantly increased firing rates by $30 \pm 9 \%(\mathrm{P}<0.05$, Mann- Whitney test), in contrast to the mere reversa1 of the effect of NOS inhibition by L-Arg. Spontaneous activity (reduced by NOS inhibition) was a1so significantly elevated, by $76 \pm 9 \%$ (Fig. 4A, filled column, left side). A similar paradigm using the chemically unrelated nitric oxide donor SNAP (Fig. 4B, hatched columns, $\mathrm{N}=7$ ) also demonstrates an excitatory effect, both on NMDA-mediated responses, increased by $37 \pm 10 \%$ ( $P<0.05$, Mann-Whitney test, right side), and on spontaneous activity, increased by $92 \pm 17 \%$ (left side). In three of these seven cells, visual responses were also tested during SNAP application. Figure 4C illustrates the effect of SNAP application on the visual responses of an ON X cell to a bar of light moved through the receptive field. Control responses are shown on the left, and responses during SNAP application on the right. As with all cells tested, there is a clear enhancement of both the visual and the spontaneous activity. 

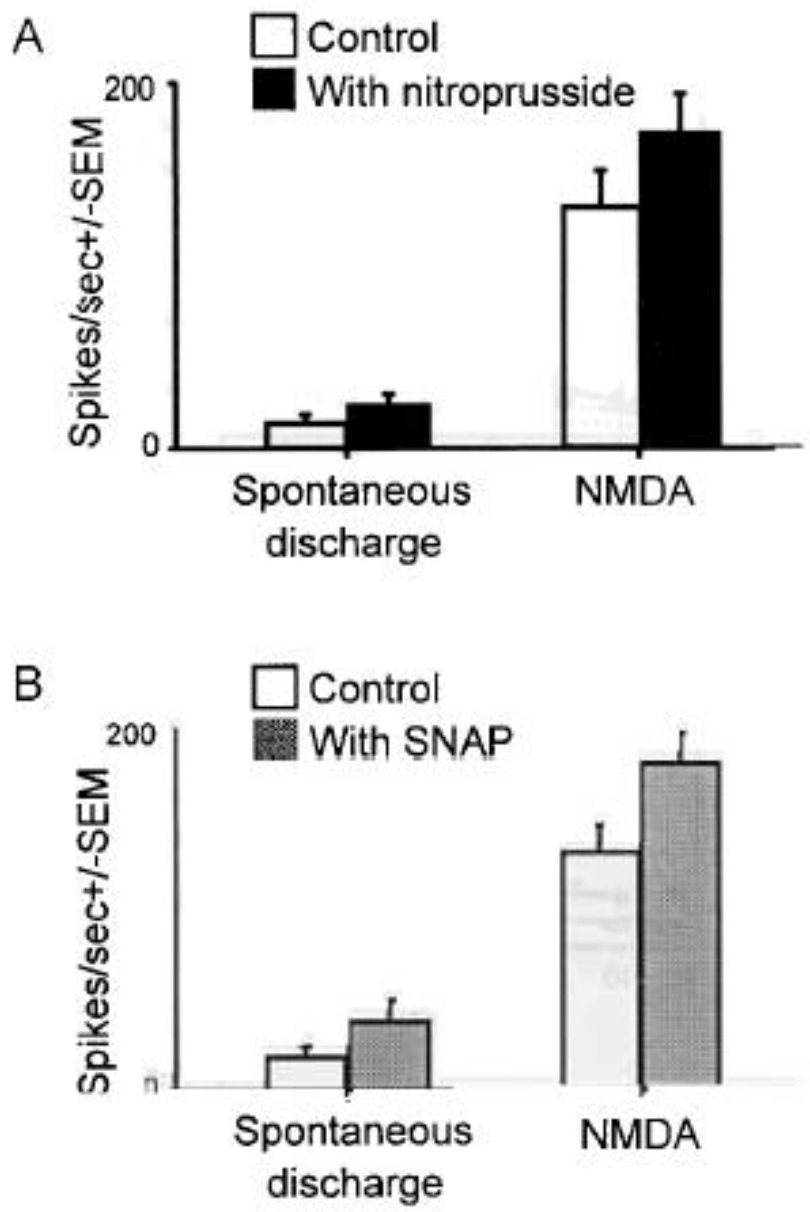

C

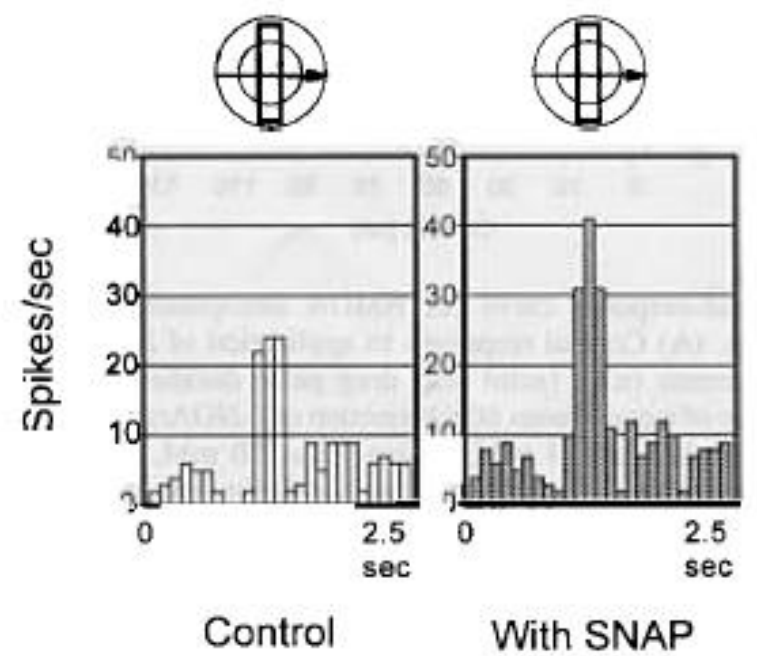

FIG. 4. (A) Application of the nitric oxide donor nitroprusside. The block histogram shows (left) the facilitatory effect of application of nitroprusside (filled column) on spontaneous activity (open column), and (right) NMDA alone (open column) and NMDA + nitroprusside (filled column), increasing the response by some $30 \%$ (P<0.05, Mann-Whitney test). (B) The effect of the nitric oxide donor SNAP. Details as for Figure 4A. SNAP enhanced NMDA-mediated excitation by $37 \%$ (P < 0.05 , Mann-Whitney test) (C) Application of the nitric oxide donor SNAP during visual stimulation. The visual stimulus was a bar of light moved through the receptive field (diagram above the records). The control response to a drifting bar of light is shown on the left, and the SNAP-augmented response on the right. On average visual responses were enhanced by $51 \%$ and spontaneous activity by $56 \%$. 
Although we have previously demonstrated that the interaction between nitric oxide and NMDA is specific to NMDA, with little or no interaction between nitric oxide and other amino acid and nonamino acid excitants in the dLGN (Cudeiro et al., 1994b), the possibility remains .tha.t such specific effects of NOS inhibitors are the resul.t of simple membrane hyperpolarization, lowering the membrane po.tentia1 below the effective range for voltage-dependent NMDA receptors (Mayer et al., 1984; Nowak et al., 1984). To control for this, in eigh.t cells we compared the responses .to NMDA application before and during application of L-NOArg with .those obtained in the presence of continuous application of GABA at levels a1so effectively reducing spontaneous activity. We suggest. that such lowering of firing activity is likely .to be the result of GABAA-mediated hyperpolarization. These data are exemplified by the responses of the cell shown in Figure 5 to pulsatile application of NMDA (hatched columns). A clear reduction in spontaneous activity was seen during L-NOArg (open columns) or GABA application (solid columns). However, NMDA responses were essentially absent only during L-NOArg application; significant excitatory responses to application of NMDA during GABA application remained.

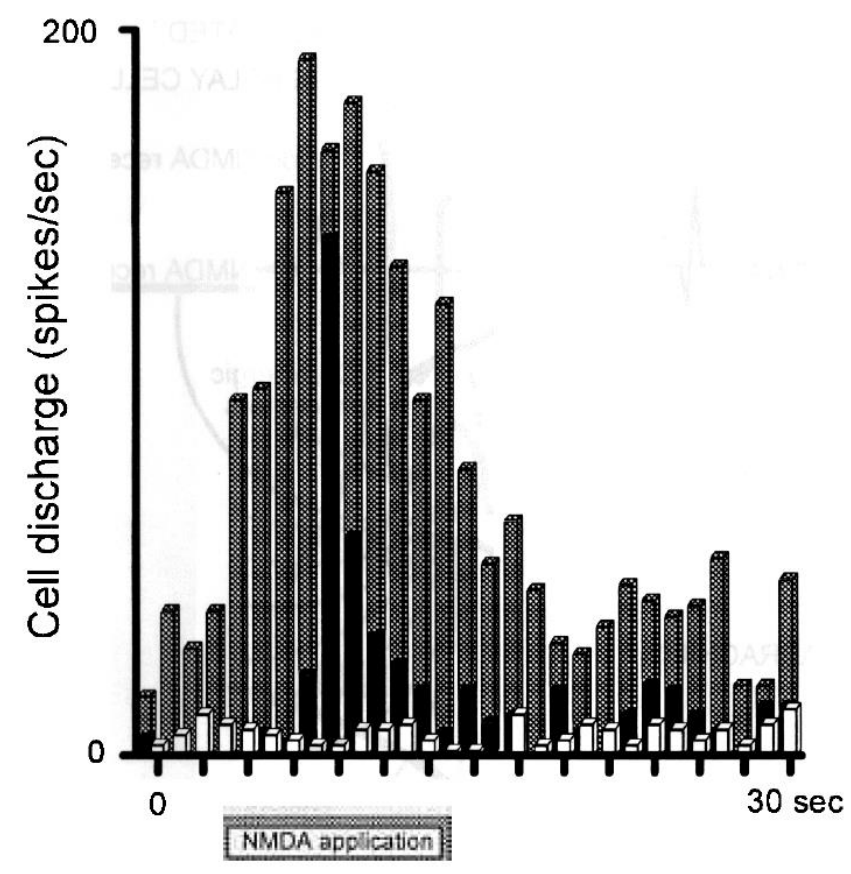

FiG. 5. Peristimulus time histograms (PSTHs) documenting the comparative effect of L-NOArg and GABA on NMDA-evoked activity. Responses to a pulse of NMDA alone ( $90 \mathrm{nA}$. hatched columns; ejection period marked below the $\mathrm{X}$ axis) in the presence of continuous L-NOArg application (open columns) or GABA (solid columns). Note that application of L-NOArg and GABA resulted in a similar decrease in spontaneous activity. Although reduced in magnitude. a clear NMDA-evoked response remained during GABA application. Bin size $1 \mathrm{~s}$.

\section{Presynaptic versus postsynaptic locus of action}

Extracellular recordings in vivo cannot directly address the issue of a presynaptic versus a postsynaptic locus of action for nitric oxide-mediated modulation of NMDA-induced activity. Nevertheless, we can indirectly investigate this problem. In four animals ail main afferent inputs to the dLGN were removed (retina, visual cortical areas 17 and 18 and brainstem; see Materials and methods), and after a waiting period of up to $48 \mathrm{~h}$ recordings were obtained from cells ipsilateral to the removed eye. After this waiting period, evoked activity following optic nerve stimulation within the deprived lamina disappeared, while significant visual activity remained in the non-visually deprived lamina (inset in Fig. 6). Thus we believe transmitter release from the deafferented axonal terminals within lamina $\mathrm{Al}$ was completely disrupted. NMDA, L-NOArg and nitroprusside were tested in layer Al on a population of ten cells, whose responses are summarized in the histogram in Figure 6B. In such deafferented animals LNOArg was essentially ineffective in reducing NMDA mediated excitation (open column NMDA, 
hatched column NMDA + L-NOArg, not significantly different, Mann-Whitney test), aithough the NMDA-mediated responses were also reduced in comparison to control responses in non-deafferented animals (data not shown) and spontaneous activity was aiso reduced. However, when nitroprusside was applied, NMDA-induced excitatory responses were strikingly increased (filled column, from $41 \pm 4.7$ to $129 \pm 23.5$ spikes/s, $\mathrm{p}<0.000$, Mann-Whitney test).
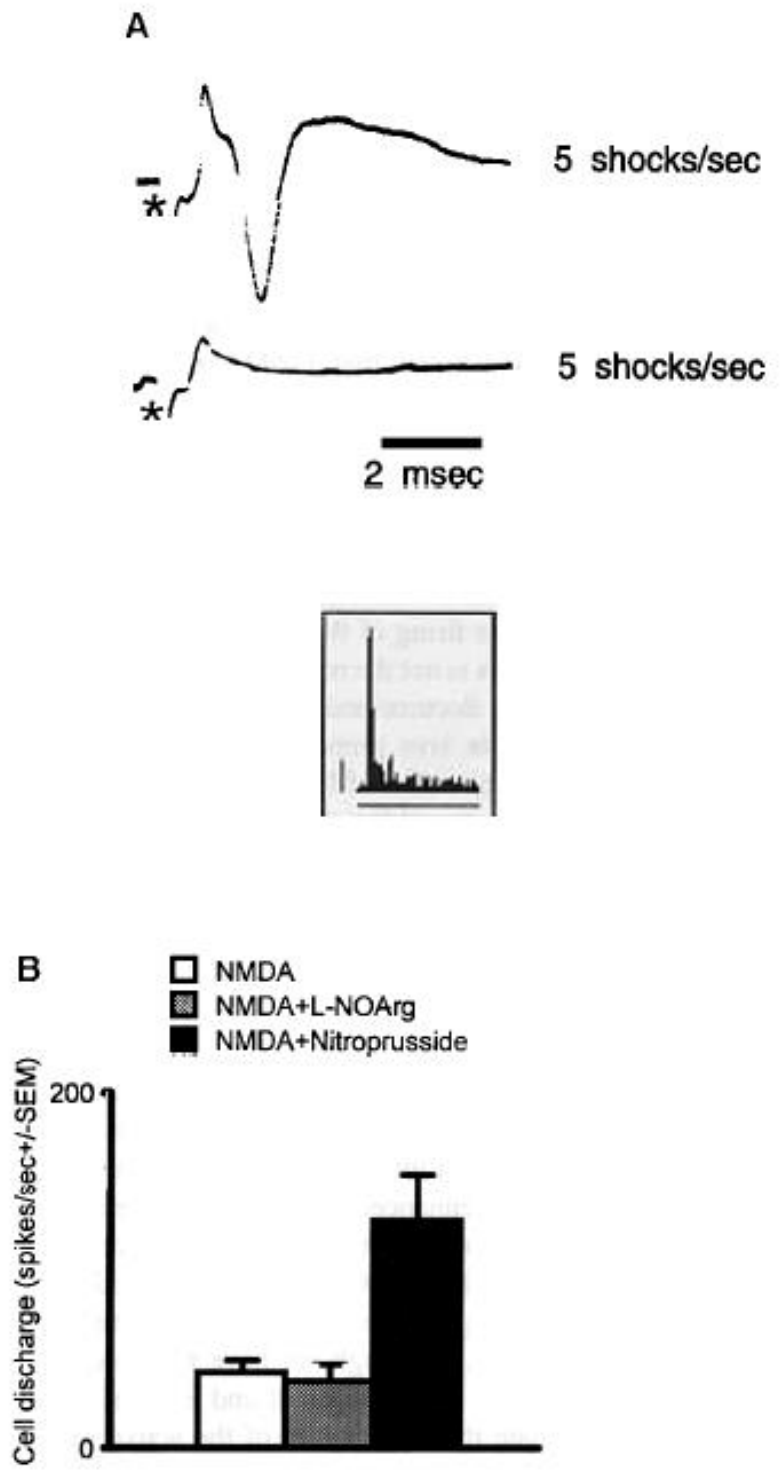

FIG 6. (A) The average of 32 single sweeps, each sweep representing the field potential elicited by a single electrical shock to the optic nerve $(0.1 \mathrm{~ms}$, up to $1 \mathrm{~mA}$ ) recorded in lamina $\mathrm{Al}$ of animals just prior to deafferentation (see Materials and methods). The lower trace documents the record obtained when the electrode was within lamina $\mathrm{Al}$, normally receiving input from the deafferented eye, after the waiting period ( $48 \mathrm{~h}$ after deafferentation). The stimulus artefact is marked (asterisk). The inset illustrates the response obtained from an ON y cell driven by the intact eye after the deafferentation period. The stimulus was a spot of light of optimum diameter flashed over the receptive field. Small vertical bar, 10 spikesls; horizontal bar shows the light-on period, $0.5 \mathrm{~s} ; 7$ trials. (B) Responses to NMDA and NMDA + LNOArg in deafferented animals (ten cells). While L-NOArg was unable to reduce the remaining NMDA-mediated excitation, application of nitroprusside markedly increased responses to NMDA. 


\section{Discussion}

The data we have presented above attempt to address a number of issues related to our earlier observations regarding nitric oxide in the cat dLGN. Previously we have shown that iontophoretic application of the putative inhibitors of the enzyme NOS markedly depressed visually elicited responses. This depression was shown to be specific, such that activity mediated via NMDA receptors, known to contribute heavily to visual responses (Kemp and Sillito, 1982; Hartveit and Heggelund, 1990; Heggelund and Hartveit, 1990; Scharfman et al., 1990; Sillito et al., 1990a, b; Kwon et al., 1991) were selectively depressed, whereas responses to other excitants, including ACh, were almost unaffected (Cudeiro et al., 1994b). A direct action of nitric oxide inhibitors themselves on NMDA receptors is unlikely as it has been convincingly demonstrated that L-NOArg has no effect on NMDA-induced membrane currents, and does not affect $\left[{ }^{3} \mathrm{H}\right]$ MK- 801 binding to NMDA receptors (Dawson et al., 1991). The finding above, that the effects of L-NOArg and L-MeArg are reversed by coapplication of L- but not D-arginine, argues for a stereo-specific lifting of the block of the enzyme, a block which seems competitive in view of the doseresponse curves illustrated in Figure 3. Furthermore, the use of GABA to inhibit the firing of the dLGN cells argues that this action of the NOS inhibitors is not the result ofnon-specific inhibition. It has previously been well documented that GABA inhibits the firing of cat dLGN cells in an in vivo preparation similar to ours by an action reversible by co-application of bicuculline (Sillito and Kemp, 1983; Vidyasagar, 1984; Pape and Eysel, 1986), suggesting a GABAA receptor-mediated hyperpolarization due to increased $\mathrm{Cl}^{-}$conductance (Eccles et al., 1977). We therefore suggest that this action of nitric oxide is the result of a specific interation with the NMDA mediated response.

One of the most interesting facets of these data is the finding that, at any application current, L-Arg itself, while antagonizing the block of nitric oxide production, produces no further increase in firing, regardless of the level of stimulation using exogenously applied NMDA. Since application of a nitric oxide donor (sodium nitroprusside or SNAP) significantly enhanced responses to this excitant under similar circumstances, we propose that in normal function, at least in the anaesthetized cat, available NOS (the enzyme producing nitric oxide) is fully active, being a rate-limiting step in the control of NMDAmediated excitation. A1though we have no direct evidence, given the $\mathrm{Ca}^{2+}$-dependence of NOS (Bredt and Snyder, 1990), it is also tempting to speculate that availability of the active form of the enzyme, and hence the leve1 of nitric oxide, is in fact modulated by activity levels of the parabrachial input, with increased spiking activity resulting in increased intracellular leve1s of $\mathrm{Ca}^{2+}$ within terminals. Such a mechanism is in contrast to many of the previously held views regarding the functional role of nitric oxide. In the current literature, two main routes of activity have been proposed for nitric oxide within the CNS. Firstly, nitric oxide may be produced in postsynaptic structures in response to incoming excitatory inputs, probably mediated by excitatory amino acids. Such postsynaptic production leads to rapid diffusion to nearby structures and emphasis has been placed on a presynaptic locus of action, resulting in modulation of subsequent transmitter release. This is the route favoured for the induction of hippocampallong term potentiation by NO (Bohme et al., 1991; O'Dell et al., 1991; Schuman and Madison, 1991; Haley et al., 1992; Izumi et al., 1992). Similar mechanisms have been proposed for induction of cerebellar long-term depression (Ito and Karachot, 1990; Shibuki and Okada, 1991). It is clear from the known anatomical location of NOS within the dLGN that such an action is unlikely, at least in the form suggested. A second model of nitric oxide function, in the main based upon work in the peripheral nervous system, has suggested a more traditional role for nitric oxide, as a neurotransmitter released from peripheral nerves innervating such structures as blood vessels and smooth muscle (Bult et al., 1990; Desai et al., 1991; see a1so Moncada et al., 1991). Such a mode1 is more 1ike1y in the case ofthe dLGN, given the exclusive1y presynaptic location of NOS (Bickford et al., 1993). In anima1s largely deprived of afferent input, NOS inhibitors were much less effective, indicating removal of functiona1 NOS by transection of the brainstem cholinergic input. The effectiveness of nitroprusside in markedly boosting responses to NMDA in these animals suggests that the action of nitric oxide is postsynaptic. Furthermore, while transection of the brainstem removed normal NOS activity, it a1so rendered NMDA application less effective, suggesting the requirement of NOS activity for full expression of NMDA-mediated excitation. Further work is in hand to examine this result in more detail.

Our findings initially seem puzzling since nitric oxide produces an effect opposite to that which has been reported by several groups working with isolated cel1s, i.e. that nitric oxide directly inhibits NMDA channels (Manzoni et al., 1992; Lei et al., 1992). This inhibitory action may be explained by observations that nitric oxide can nitrosylate the NMDA receptor, thus blocking glutamate neurotransrnission and as a result producing neuroprotection (Lei et al., 1992; Lipton et al., 1993). Even using methods which do not allow us to interpret our results at the receptor level, it seems clear that nitric oxide facilitates excitation evoked by NMDA, not the opposite. How can this discrepancy be exp1ained? One possible explanation is that nitric oxide can exist in distinct oxidation-reduction states which have different biological actions (Lipton et al., 1993). Thus, reaction of NO- (the reduced form) with superoxide can lead to neurotoxicity 
through the formation of peroxynitrite, whereas nitric oxide alone does not. On the other hand, reaction of $\mathrm{NO}+$ (the oxidized form) with thiol groups on the NMDA receptor can lead to neuroprotection by inhibiting $\mathrm{Ca}^{2+}$ influx (Lipton et al., 1993; Lipton and Stamler, 1994). Thus a nitric oxide donor, e.g. nitroprusside, may have either neuroprotective or neurotoxic effects depending on the local redox milieu of the biological system (Lipton et al., 1993; Lipton and Stamler, 1994). However, this problem is much more complicated than was first thought, as it has been recently shown using slices of rat cerebellum and hippocampus that nitric oxide mediates neither acute glutamate neurotoxicity nor neuroprotection (Garthwaite and Garthwaite, 1994). It is clear that our in vivo paradigm differs greatly from those used in the studies related to above and this may, at least in part, contribute to the differences in our data. Other studies, more closely related to our own in vivo work, offer further insight. Do et al. (1994) have described release of arginine in the ventrobasal thalamus of adult rats in vivo following physiological stimulation of sensory afferents. While such release alone should not augment the production of nitric oxide, as judged by the action of L-Arg we have outlined above, if coupled with a $\mathrm{Ca}^{2+}$-mediated enzyme activation it would markedly increase nitric oxide production. It remains possible that nitric oxide has multiple functions within sensory thalamus. Pape and Mager (1992), in the cat LGN in vitro, found that release of nitric oxide on thalamocortical neurons had a direct postsynaptic effect which caused depolarization from the membrane resting potential associated with a decrease in input resistance, but which appeared only at membrane potentials negative to $-65 \mathrm{mV}$. These small depolarizations appeared to act via the cGMP secondary messenger system, and be related to control of oscillatory firing patterns. This cGMP-mediated action of nitric oxide may be involved in the control of different patterns of electrogenic activity during various states of the sleep/wake cycle (Pape and Mager, 1992). However, we have previously shown that the effects of NOS blockade outlined above do not operate via control of the cGMP cascade, since the soluble cGMP analogue 8-bromo-cGMP [the compound used by Pape and Mager (1992) did not affect NMDA-mediated excitation (Cudeiro et al., 1994b) or, as we have now shown above, mimic the effect of sodium nitroprusside or SNAP.

In summary, the most parsimonious view of our data suggests that within the cat dLGN, where NOS is located only within the terminals of parabrachial input (Bickford et al., 1993), one action of NO is to enhance or permit full expression of NMDA-mediated activity. At the level of the dLGN there are three possible sites for the nitric oxide action: cells within the nucleus, presynaptic terminals impinging on these cells, or both. Within the cerebral cortex it has been suggested that nitric oxide affects neurotransmitter release subsequent to NMDA receptor activation, in a study confirming a facilitatory action of nitric oxide on NMDA function, at this level enhancing presynaptic NMDA control of transmitter release (Montague et al., 1994). Direct effects on the regulation of neurotransmitter release have been reported from a number of brain areas, including the striatum (Black et al., 1994), the hippocampus (Lonart et al., 1992) and the medial preoptic area (Lorrain and Hull, 1993). However, our data using deafferented animals clearly suggest a straightforward postsynaptic action of nitric oxide, as seen from the action of sodium nitroprusside. We have illustrated this diagrammatically in Figure 7. Clearly, the highly diffusible gas nitric oxide may act in the proximity of the synaptic area of the parabrachial terminals, diffusing to act on retinogeniculate or other synapses utilizing NMDA receptors, perhaps also on neighbouring cells. Thus, release of nitric oxide may facilitate visual transmission in the tha1amus affecting simultaneously the functional activity of a neuronal population in an extended volume of tissue. It has been predicted from a theoretical model that the sphere of influence of a single point source of nitric oxide has a diameter of $\sim 200 \mu \mathrm{m}$, corresponding to a volume of brain enclosing 2 000000 synapses (Wood and Garthwaite, 1994). This system of control must be of a more global nature than normal synaptic transmission, but may act in concert with the more discrete spiking activity of the cholinergic input. The potency of this mechanism can clearly be seen from the extremely effective reduction of visual responses during blockade of NOS. Thus, in conclusion, we suggest that this pathway is of critical importance to the normal transfer of visual information from the retina through the dLGN to the cortex, utilizing nitric oxide to control this 'gateway' for vision.

\title{
Acknowledgements
}

We are indebted to Dr A. Canedo for his help in the electrical stimulation experiments. This work was supported by DGICYT (PB93-0347), Spain.

\author{
Abbreviations \\ ACh acetylcholine \\ EEG electroencephalograrn \\ ECG electrocardiograrn \\ cGMP cyclic guanosine-3',5'-mono-phosphate
}


CNS central nervous system

dLGN dorsallateral geniculate nucleus

GABA Y-aminobutyric acid

D-Arg D-arginine

L-Arg L-arginine

L-MeArg $N^{G}$-methyl-L-arginine

L-NOArg $N^{G}$-nitro-L-arginine

NMDA N-methyl-D-aspartate

NOS nitric oxide synthase

PSTH peristimulus time histograrn

SNAP $S$-nitroso- $N$-acetylpenicillamine

\section{References}

Bickford, M. E., Günlük, A. E., Guido, w. and Sherman, S. M. (1993) Evidence that cholinergic axons from the parabrachial region of the brainstem are the exclusive source of nitric oxide in the latera1 geniculate nucleus of the cat. J. Comp. Neurol., 334, 410-430.

Black, M. D., Matthews, E. K. and Humphrey, P. A. (1994) The effects of a photosensitive nitric oxide donor on basa1 and electrica1-stimulated doparnine efflux from the rat striatum in vitro. Neuropharmacology, 33, 13571365.

Bohme, G. A., Bon, C., Stutzmann, J.-M., Doble, A. and Blanchard, J.-C. (1991) Possible involvement of nitric oxide in long-terrn potentiation. Eul: J. Pharmacol., 199, 379-381.

Bredt, D. S. and Snyder, S. H. (1990) Isolation of nitric oxide synthetase, a ca1modulin-requiring enzyme. Proc. Natl Acad. Sci. USA, 87,682-685.

Bult, H., Boeckxstaens, G. E., Pelckmans, P. A., Jordaens, F. H., Vanmaercke, Y. M. and Herrnan, A. G. ( 1990) Nitric oxide as an inhibitory non-adrenergic non-cholinergic neurotransmitter. Nature, 345, 346-347.

Cleland, B. G., Dubin, M. W. and Levick, w. R. (1971) Sustained and transient neurones in the cat's retina and lateral geniculate nucleus. J. Physiol. (Lond.), 217, 473--496.

Cudeiro, J., Rivadulla, C., Rodríguez, R., Martínez-Conde, S., Acuña, C. and Alonso, J. M. (1994a) Modulatory influence of putative inhibitors of nitric oxide synthesis on visual processing in the cat lateral geniculate nucleus. J. Neurophysiol., 71, 146-149.

Cudeiro, J., Grieve, K. L., Rivadulla, C., Rodríguez, R., Martínez-Conde, S. and Acuña, C. (1994b) The role of nitric oxide in the transformation of visual information within the dorsal lateral geniculate nucleus of the cat. Neuropharmacology,33, 1413-1418.

Dawson, V. L., Dawson, T. M., London, E. D., Bredt, D. S. and Snyder, S. H. ( 1991) Nitric oxide mediates glutamate neurotoxicity in primary cortica1 cultures. Proc. Natl Acad. Sci. USA, 88,6368-6371.

Dawson, v. L., Dawson, T. M., Bartley, D. A., Uhl, G. R. and Snyder, S. H. ( 1993) Mechanisms of nitric oxidemediated neurotoxicity in primary brain cultures. J. Neurosci., 13,2651-2661.

Derrington, A. M. and Fuchs, A. F. (1979) Spatial and temporal properties of X and y cells in the cat latera1 geniculate nucleus. J. Physiol. (Lond.), 293, 347-364.

Desai, K. M., Sessa, W. C. and Vane, J. R. (1991) Involvement of nitric oxide in the reflex relaxation of the stomach to accommodate food or fluid. Nature, 351, 477-479.

Do, K.-Q., Binnst, K. E. and Salt, T. E. (1994) Release of the nitric oxide precursor, arginine, from the thalamus upon sensory afferent stimulation, and its effect on tha1arnic neurons in vivo. Neuroscience, 60, 581-586.

Eccles, J. C., Nicoll, R. A., Oshima, T. and Rubia, F. J. (1977) The anionic permeability of the inhibitory postsynaptic membrane of hippocampal pyramidal cells. Proc. R. Soc. Lond., 198,345-361.

Enroth-Cugell, C. and Robson, J. G. (1967) The contrast sensitivity of retinal ganglion cells in the cat. J. Physiol. (Lond.), 187,517-552.

Eysel, U. T., Pape, H.-C. and Van Schayck, R. (1986) Excitatory and differential disinhibitory actions of acetylcholine in the lateral geniculate nucleus of the cat. J. Physiol. (Lond.), 370, 233-254.

Funke, K. and Eysel, U. T. (1992) EEG-dependent modulation of response dynamics of cat dLGN relay cells and the contribution of corticofuga1 feedback. Brain Res, 573,217-227.

Garthwaite, J. (1991) Glutamate, nitric oxide and cell-cell signalling in the nervous system. Trends Neurosci., 14,6067.

Garthwaite, G. and Garthwaite, J. (1994) Nitric oxide does not mediate glutamate neurotoxicity, nor is it neuroprotective, in rat brain slices. Neuropharmacology,33, 1431-1438.

Garthwaite, J., Charles, S. L. and Chess-Williams, R. (1988) Endotheliumderived relaxing factor release on activation of NMDA receptors suggests role as intercellular messenger in the brain. Nature, 336, 385-388.

Haley, J. E., Wilcox, G. L. and Chapman, P. F. (1992) The role of nitric oxide in hippocampa11ong-term potentiation. Neuron, 8,211-216.

Hartveit, E. and Heggelund, P. (1990) Neurotransmitter receptors mediating excitatory input to cells in the cat lateral geniculate nucleus. II. Non-lagged cells. J. Neurophysiol., 63, 1361-1372.

Heggelund, P. and Hartveit, E. (1990) Neurotransmitter receptors mediating excitatory input to cells in the cat latera1 geniculate nucleus. I. Lagged cells. J. Neurophysiol., 63, 1347-1360. 
Ito, M. and Karachot, L. (1990) Messengers mediating long-term desensitization in cerebellar Purkinje cells. NeuroReport, 1, 129-132.

Izumi, Y., Clifford, D. B. and Zorumsky, C. F. (1992) Inhibition of long term potentiation by NMDA-mediated nitric oxide release. Science, 257, 1273-1276.

Kemp, J. A. and Sillito, A. M. (1982) The nature of the excitatory transmitter mediating X and y cell inputs to the cat dorsal lateral geniculate nucleus. J. Physiol. (Lond.), 323, 377-391.

Kwon, Y. H., Esguerra, M. and Sur, M. (1991) NMDA and non-NMDA receptors mediate visual responses of neurons in the cat latera1 geniculate nucleus. J. Neurophysiol., 66, 414-428.

Lei, S. Z., Pan, Z.-H., Aggarwal, S. K., Chen, H.-S. V., Hartman, J., Sucher, N. J. and Lipton, S. A. (1992) Effect of nitric oxide production on the redox modulatory site of the NMDA receptor-channel complex. Neuron, 8, 10871099.

Lipton, S. A., Choi, Y.-B., Pan, Z.-H., Lei, S. Z., Chen, H.-S. V., Sucher, N. J., Losca1zo, J., Singel, D. J. and Stamler, J. S. (1993) A redox-based mechanism for the neuroprotective and neurodestructive effects of nitric oxide and related nitroso-compounds. Nature, 364, 626-632.

Lipton, S. A. and Stamler, J. S. (1994) Actions of redox-related congeners of nitric oxide at the NMDA receptor. Neuropharmacology, 33, 1229-1233.

Lo, F. S. and Sherman, S. M. (1994) Feedback inhibition in the cat's lateral geniculate nucleus. Exp. Brain Res., 100, 365-368.

Lonart, G., Wang, J. and Johnson, K. M. (1992) Nitric oxide induces neurotransmitter release from hippocampal slices. Eul: J. Pharmacol., 220, 271-272.

Lorrain, D. S. and Hull, E. M. (1993) Nitric oxide increases dopamine and serotonine release in the medial preoptic area. NeuroReport, 5, 87-89.

Lundberg, J. M., Anggard, A., Fahrenkrug, J., Hokfelt, T. and Mutt, V. (1980) Vasoactive intestinal polypeptide in cholinergic neurons of exocrine glands: functional significance of coexisting (transmitters for vasodilation and secretion. Proc. Natl Acad. Sci USA, 77, 1651-1655.

Manzoni, O., Prezeau, L., Marin, P., Deshager, S., Bockaert, J. and Fagni, L. (1992) Nitric oxide-induced blockade of NMDA receptors. Neuron, 8, 653-662.

Mayer, M. L., Westbrook, G. L. and Guthrie, P. B. (1984) Voltage dependent block by Mg2+ of NMDA responses in spinal-cord neurons. Nature, 309, 261-263.

McConnick, D. A. (1992) Neurotransmitter actions in the thalamus and cerebral cortex and their role in neuromodulation of thalamocortical activity. Progress Neurobiol., 39, 337-388.

McConnick, D. A. and Pape, H.-C. (1988) Acetylcholine inhibits identified interneurons in the cat lateral geniculate nucleus. Nature, 334, 246-248.

McConnick, D. A. and Von Krosigk, M. (1992) Corticothalamic activation modulates thalamic firing through glutamate metabotropic receptors. Proc. Natl Acad. Sci. USA, 89, 2774-2778.

Moncada, S., Palmer, R. M. J. and Higgs, E. A. (1991) Nitric oxide: physiology, pathophysiology, and phannacology. Phannacol. Rev., 43, 109-142.

Montague, P. R., Gancayco, C. D., Winn, M. J., Marchase, R. B. and Friedlander, M. J. (1994) Role of No production in NMDA receptor mediated neurotransmitter release in cerebral cortex. Science, 263, 973-977.

Mutphy, P. C. and Sillito, A. M. (1987) Corticofugal feedback influences the generation of length tuning in the visual pathway. Nature, 329, 727-729.

Nowak, L., Bretestovski, P., Ascher, P., Herbet, A. and Prochiantz, A. (1984) Magnesium ates glutamate-activated channels in mouse central neurones. Nature, 307,462-465.

O'Dell, T. J., Hawkins, R. D., Kandel, E. R. and Arancio, O. (1991) Test of the roles of two diffusible substances in long-term potentiation: evidence for nitric oxide as a possible early retrograde messenger. Proc. Natl Acad. Sci. USA, 88, 11285-11289.

Pape, H. C. and Eysel, U. T. (1986) Binocular interactions in the lateral geniculate nucleus of the cat-GABAergic inhibition reduced by dominant eye afferent activity. Exp. Brain. Res., 61,265-271.

Pape, H. C. and Mager, R. (1992) Nitric oxide controls oscillatory activity in thalamocortical neurons. Neuron, 9,441448.

Scharfman, H. E., Lu, S.-M., Guido, W., Adams, P. R. and Shennan, S. M. (1990) N-methyl-D-aspartate receptors contribute to excitatory postsynaptic potentials of cat lateral geniculate neurons recorded in thalamic slices. Proc. Natl Acad. Sci. USA, 87,4548-4552.

Schuman, E. M. and Madison, D. V. (1991) A requirement for the intercellular messenger nitric oxide in long-term potentiation. Science, 254, 1503-1506.

Schuman, E. M. and Madison, D. V. (1994) Nitric oxide and synaptic function. Annu. Rev. Neurosci., 17, 153-183.

Shibuki, K. and Okada, D. (1991) Endogenous nitric oxide release required for long-term synaptic depression in the cerebellum. Nature, 349, 326-328.

Sillito, A. M. and Kemp, J. A. (1983) The influence of GABAergic inhibitory processes on the receptive-field structure of X-cells and Y-cells in cat dorsal lateral geniculate nucleus (dLGN). Brain Res., 277,63-77.

Sillito, A. M., Kemp, J. A. and Berardi, N. (1983) The cholinergic influence on the function of the cat dorsallateral geniculate nucleus (dLGN). Brain Res.. 280, 299-307.

Sillito, A. M., Mutphy, P. C., Salt, T. E. and Moody, C. I. (1990a) The dependence of retinogeniculate transmission in the cat on NMDA receptors. J. Neurophysiol., 63, 347-355.

Sillito, A. M., Mutphy, P. C. and Salt, T. E. (1990b) The contribution of the non-N-methyl-D-aspartate group of amino-acid receptors to retinogeniculate transmission in the cat. Neuroscience, 34, 347-355. 
Sillito, A. M., Cudeiro, J. and Mutphy, P. C. (1993) Orientation sensitive elements in the corticofugal influence on centre-surround interactions in the dorsallateral geniculate nucleus. Exp. Brain. Res., 93,6-16.

Sillito, A. M., Jones, H. E., Gerstein, G. L. and West, D. C. (1994) Featurelinked synchronization of thalamic relay cell firing induced by feedback from the visual cortex. Nature, 369, 479-482.

Singer, W. (1977) Control of thalamic transmission by corticofugal and ascending reticular pathways in the visual system. Physiol. Rev.. 57, 386-420.

Snyder, S. H. and Bredt, D. S. (1991) Nitric oxide as a neuronal messenger. Trends Phannacol. Sci., 12, 125-128.

Steriade, M. and Llinás, R. R. (1988) The functional states of the thalamus and the associated neuronal intetplay. Physiol. Rev., 68, 649-742.

Vidyasagar, T. R. (1984) Contribution of inhibitory mechanisms to the orientation sensitivity of cat dLGN neurones. Exp. Brain Res., 55, 192-195.

Wood, J. and Garthwaite, J. (1994) Models of the diffusional spread of nitric oxide: implications for neural nitric oxide signalling and its pharmacological properties. Neurophannacology, 33, 1235-1244. 